\title{
Ontario takes aim at painkiller abuse
}

$\mathrm{S}$ ome might call them tentative steps. But two high-level action committees - the Opioid Public Policy Project and the Narcotics Advisory Panel - were created earlier this year to address the rampant misuse of prescription painkillers and lower the rising number of Ontarians seeking treatment for opioid addiction.

The committees were established in response to data that has emerged over the past few years indicating that Ontario is becoming a hub of opioid use in Canada.

Per capita spending on opioid drugs in the province is now about $29 \%$ above the national average, according to the Canadian Rx Atlas (2nd edition, December 2008).

Meanwhile, a 2007 survey by the Toronto-based Centre for Addiction and Mental Health indicated that $21 \%$ of students from grades 7 to 12 took prescription opioids without a prescription, with more than $70 \%$ of those accessing the drugs from their own homes. Deaths involving oxycodone have also been on the rise, according to the Office of the Chief Coroner for Ontario.

"We think oxycodone is a much bigger problem than heroin," says Anton Hart, who headed the province's 2007 Methadone Maintenance Treatment task force, which identified the oxycodone abuse as a "critical issue" that should be urgently addressed, and addictions as a "widespread problem."

There has since been a 70\% increase in the number of Ontarians placed on methadone maintenance treatment for opioid addiction (about 24000 now, as compared with the 16400 identified by the task force in 2007).

Experts say drugs containing the active ingredient oxycodone are the source of much of the problem. And the consensus is that an increasing proportion of those coming to methadone treatment have a history of opioid addiction, says Wade Hillier, manager of government programs (independent health facilities and methadone) for the

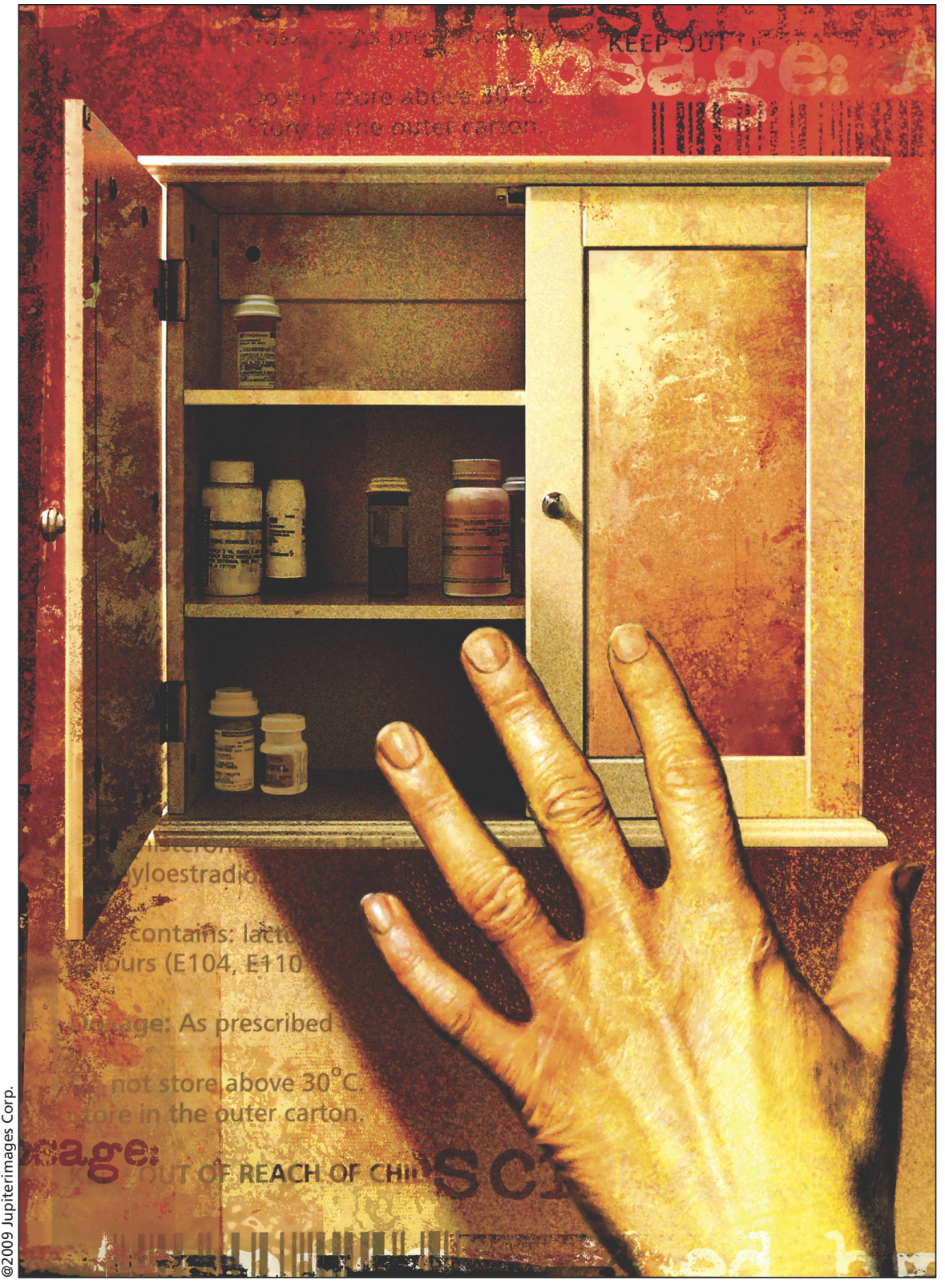

As opioids become more common in medicine cabinets because of their use in treating chronic pain, the frequency of misuse is rising.

College of Physicians and Surgeons of Ontario (CPSO).

CPSO Registrar Dr. Rocco Gerace says the multistakeholder Opioid Public Policy Project hopes to craft policy recommendations by next spring related to opioid distribution, dispensing, prescribing and diversion.
The 11-member Narcotics Advisory Panel, meanwhile, will report to the Ontario Public Drug Benefit Plan, which has seen a threefold increase in spending on oxycodone (OxyContin) over the past five years, to $\$ 65$ million in fiscal year 2008/09 from $\$ 19.3$ million in 2003/04. 
Province wide, the number of prescriptions for opioids rose to 4.7 million from 3.7 million between 2005 and 2008, according to the pharmaceutical consulting firm IMS Health, which tracks drug sales.

According to IMS data, drugs that combine acetaminophen and oxycodone (such as Percocet, Endocet, Roxicet and Tylox) were the most highly prescribed opioids in Ontario in 2008 , followed by drugs containing morphine and its derivative hydomorphone. OxyContin ranked third in sales in the opioid class, but has become a particular concern because its controlled release formula contains a higher level of the active ingredient.

Meanwhile, fatality figures from Ontario's Office of the Chief Coroner show that oxycodone was involved in an estimated 464 deaths between 2004 and 2008 , while methadone was involved in 366 deaths between 2002 and 2006. Heroin was a factor in 49 deaths. Moreover, the rate of oxycodone-related deaths nearly doubled, while those of methadone rose only marginally and those involving heroin declined.

Yet, despite such numbers, when it comes to tracking opioid prescribing, Ontario lacks the tools used by other provinces. British Columbia, for exam- ple, has a prescription review program that facilitates the identification of patients who engage in double doctoring (obtaining multiple narcotic prescriptions from different doctors), as well as the identification of physicians who may be prescribing inappropriately.

"Sadly we do not have in Ontario the ability to track these issues," says Gerace.

The College now maintains a register of physicians who prescribe methadone (between 260 and 280) and tracks the number of patients on treatment, but does not track the source of the addiction that prompted treatment.

Hiller says the College also supports other options to treat opioid addictions, such as residential withdrawal management and counselling. And he says guidelines are now being developed for the use of a substitution treatment to methadone known as buprenorphine and naloxone combination (Suboxone), for which 30000 prescriptions were written in the province during the first six months of 2009.

Developing a more multifaceted and multipronged approach to handle the problem of prescription opioid abuse will be increasingly critical to all Canadian cities as evidence suggests opioid abuse has become the predomi- nant drug problem for most urban centres (CMAJ 2006;175[11]:1385-7).

Doctors in Sudbury report that the majority of patients they place on methadone treatment are coping with oxycodone addiction and, at admission to the methadone program at Centre for Addiction and Mental Health, $82 \%$ of patients reported using prescription opioids, according to a 2004 study (Drug Alcohol Depend 2004;73:199-207).

An OxyContin/Narcotics Task Force in Sudbury, convened in 2004 after two deaths from illegal prescription opioid use, discovered that cocaine addicts were using prescription opioids to delay the rapid drop from a cocaine high, while youths were holding pill sharing parties.

"Denial is just so huge when it comes to addiction and none of us want to believe that our kids would participate in such an activity," says Vicki Kett, manager of community care at Access AIDS Sudbury and cochair of the task force. "How many people know what is in their bathroom cabinet and the harm it can cause? When people have cracked ribs, do they really need OxyContin?" - Ann Silversides, CMAJ

DOI:10.1503/cmaj.109-3032 